
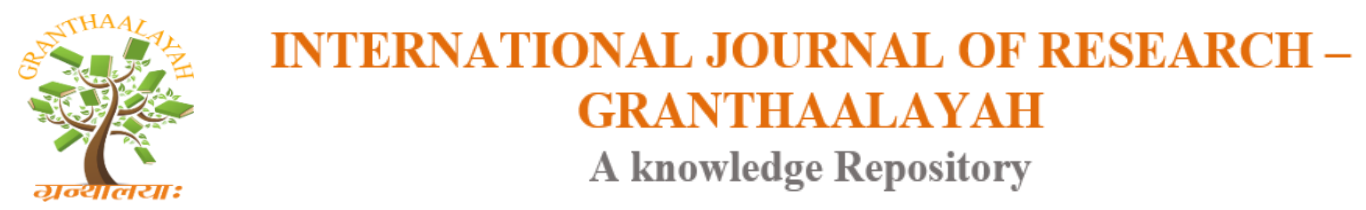

Science

\title{
A VIRTUAL SIMULATOR AS A TOOL FOR TEACHING REFRACTOMETRY
}

\author{
Francisco Irochima Pinheiro ${ }^{1}$, Eduardo Pereira de Azevedo ${ }^{1}$, Amália Cinthia Meneses \\ Rêgo ${ }^{1}$, Irami Araújo-Neto ${ }^{2}$, Irami Araújo-Filho ${ }^{3}$, Paulo Schor ${ }^{4}$ \\ ${ }^{1}$ Full Professor for the Masters in Biotechnology from the Potiguar University- LAUREATE \\ INTERNATIONAL UNIVERSITIES - Ph.D. In Health Science \\ ${ }^{2}$ Undergraduate Medical Student, Potiguar University (UnP) - Laureate International \\ Universities - Natal, Rio Grande do Norte, Brazil \\ ${ }^{3}$ Full Professor of the Department of Surgery, PhD in Health Sciences, Full Professor of the Post \\ Graduate Program in Biotechnology at Potiguar University - Laureate International Universities, \\ Natal, Rio Grande do Norte, Brazil \\ ${ }^{4} \mathrm{PhD}$ in Ophthalmology - Full Professor of the Department of Ophthalmology and Professor of \\ the Post-Graduation Courses of the Departments of Informatics in Health and Ophthalmology of \\ UNIFESP - Federal University of São Paulo (Unifesp), São Paulo, Brazil
}

\begin{abstract}
Significance: Several educational technological innovations are developed with the purpose of contributing to the training of future optometrists and ophthalmologists. However, very little is available for teaching refractometry. EYE REFRACTION is a simulator mobile applications (App) that works as a fast, straightforward and interactive interface tool for teaching refractometry. Purpose: Develop novel mobile application software (EYE REFRACTION) as a tool for teaching refractometry in medical schools. Methods: EYE REFRACTION software was developed by the emerging company "Ciência Ilustrada studio" incubated at "INOVA Metrópole" of the Digital Metropolis Institute of the Universidade Federal do Rio Grande do Norte, Brazil (IMD-UFRN), using the XCode 4.6.2. program (Apple Computer, Inc. Cupertino, CA, USA). This application software (App) was created for Tablets and has a fully interactive workspace, where after inserting the refraction data of the patient, the user can observe points or focal lines of the refractive errors and all the arrangements resulting from the various possible corrections. Results: After 90 days of blind and random simulations of the EYE REFRACTION App performed by volunteered ophthalmologists, six failures were detected and promptly corrected. Two were detected when refractive errors were simulated (simple myopic astigmatism), two during simulations of hypermetropic astigmatism, being one simple and the other compound, and two others during the simulation of mixed astigmatism. Conclusion: A novel App for teaching refractometry was successfully developed, where it enabled a real-time observation of refractive errors and their arrangements. The EYE REFRACTION App is currently available at Apple App Store.
\end{abstract}


Keywords: Refratectomy; Refractive Errors; Simulation Training; Mobile Applications; Medical Informatics.

Cite This Article: Francisco Irochima Pinheiro, Eduardo Pereira de Azevedo, Amália Cinthia Meneses Rêgo, Irami Araújo-Neto, Irami Araújo-Filho, and Paulo Schor. (2017). "A VIRTUAL SIMULATOR AS A TOOL FOR TEACHING REFRACTOMETRY." International Journal of Research - Granthaalayah, 5(10), 23-33. 10.29121/granthaalayah.v5.i10.2017.2264.

\section{Introduction}

It has been reported that the ocular health conditions of the world-wide population are related to the quality of the primary care professionals. ${ }^{1,2}$ In fact, scientific studies have shown that the use of new pedagogical approaches based on technology and interactivity towards the teaching of ophthalmology have been much more effective in the teaching-learning process than the traditionally used methodologies. ${ }^{3-5}$

In addition, teaching refractometry has always been a challenge for ophthalmology residency programs. This is explained by the fact that specific abilities are necessary in order to successfully perform a refraction test. Optometrists need to know physics, mathematics and geometry for understanding how to determine and correct the so-called refractive errors (ametropia) of the optical system. ${ }^{6}$ Therefore, there is an urgent need to train fully qualified professionals to diagnose and treat the various refractive errors through the prescription of corrective lenses. However, demographic growth has been disproportionally higher than the number of well trained professionals available to supply such demand.

The limited number of professionals responsible for prescribing corrective lenses in addition to their deficient training favor the emergence of unqualified professionals who venture into this activity, putting at risk the ocular health of the population. ${ }^{7,8}$

Nowadays, around 2.5 billion people have some degree of visual impairment due to the need for glasses where 670 million are considered visually impaired because they do not have access to the treatment with corrective lenses. ${ }^{2}$ Thus, it seems that an effective way to ameliorate the incidence of visual impairment is through the development of tools that helps training professionals to correctly diagnose and treat the various refractive errors.

The global initiative known as "Vision 2020: The Right to Sight", a result of the partnership between the World Health Organization (WHO) and the International Agency for the Prevention of Blindness (IAPB), suggests several strategies for the prevention of visual impairment due to refractive errors. One of the recommended strategies is to encourage investment in the development and training of human resources, which would eventually result in better ophthalmic examinations that are accessible to the population. Moreover, another strategy is to increase the ratio between the numbers of qualifying prescribers to 1.5 per 100,000 habitants until $2020 .^{2}$

Therefore, the development of teaching tools in the form of application software (App) might speed up the training process, leading to a shorter learning time. This tool would be beneficial for 
residents as well as for those professionals that need to learn new techniques. In addition, this App might represent a useful strategy to minimize errors during prescription of corrective lenses.

The aim of this technical report is to present a new simulator App that works as a fast, straightforward and interactive interface tool for teaching refractometry to future ophthalmologists. The use of this App by ophthalmology residency programs would enable the formation of better qualified professionals, which is what WHO advocates.

\section{Material and Methods}

The EYE REFRACTION software was developed and tested over a period of 8 months, from March to October 2011, by the emerging company "Ciência Ilustrada studio" incubated at "INOVA Metrópole" of the Federal University of Rio Grande do Norte (IMD-UFRN, Natal, Brazil).

\subsection{Graphic Development and Software Programming}

The drawings used to illustrate the App were created using the CorelDRAW X8 program (Corel Corporation, Ottawa, Canada), which was performed by the ophthalmologist and one of the authors of this current work (Pinheiro, FI). Software programming was coded using XCode 4.6.2 software (Apple Computer, Inc. Cupertino, CA, and USA) and performed by an experienced programmer and also one of the authors of this work (Souza, EP). The App was created for Tablets on the IOS platform (IPhone OS), where an initial work area containing a top tab (Patient's Actual Refraction) is used to insert the refractometry data: spherical (Sph) from -10.00 to +10.00 diopters (D), at intervals of 0.01 , and cylindrical (Cyl) from -10.00 to $+10.00 \mathrm{D}$, at intervals of 0.01 with their respective axis from $0^{\circ}$ to $180^{\circ}$, at intervals of $1^{\circ}$. A column on the right side of the screen, named CORRECTION, containing the following tabs: Lens \# 1, Lens \# 2, Lens Power, Patient Residual Refraction, SER (Spherical Equivalent Refractive) and Sagittal View. The Lens \# 1 and Lens \# 2 tabs have the None, Sph, and Cyl options according to the type of correction the professional wants to simulate. If Sph or Cyl is chosen, a box will appear to add the numerical values with buttons to fine-tune to 2 decimal places.

At the center of the screen, a graphic representation of the eyeball is displayed in partial and perspective sections. In addition, the top left of the central screen shows a frontal representation of the optical system with two meridians perpendicular to each other, which is named Front Power. Above and to the left of the Front Power is the Show Astigmatism key. Once triggered, it presents the simulation of the theoretical astigmatism of the system. The lower right portion of the eyeball shows the type of ametropia (refractive error) or emmetropia according to the entry values added in the Patient Actual Refraction tab (Figure 1). 


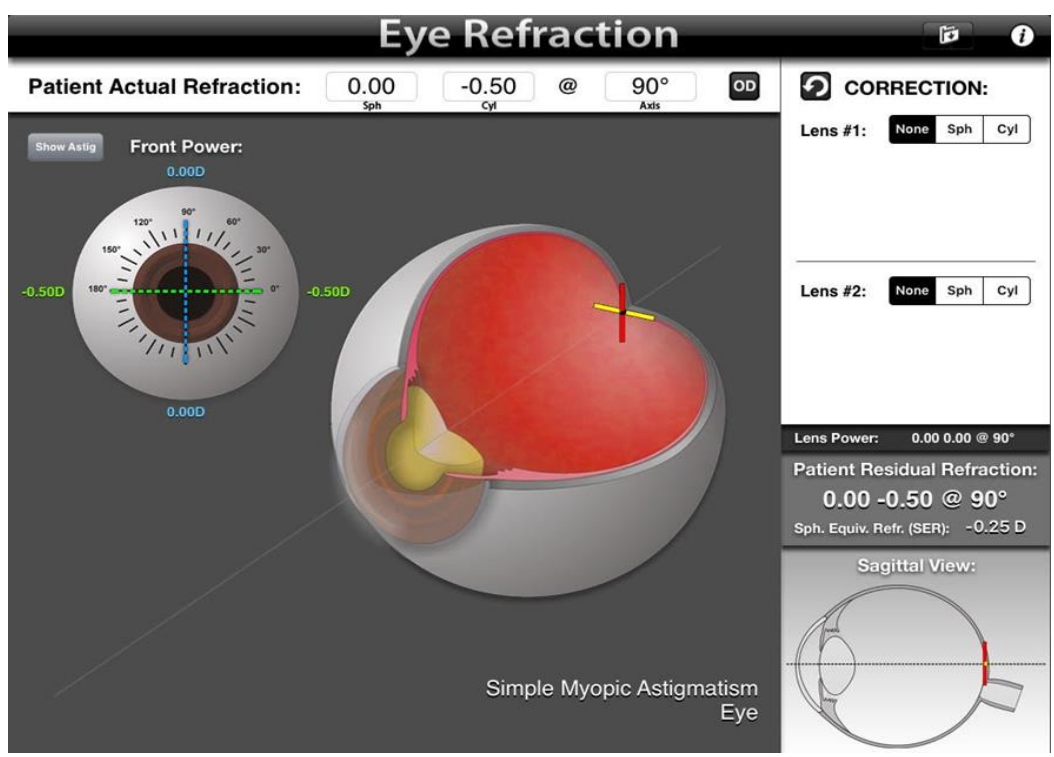

Figure 1: Eye Refraction main screen layout

By inserting positive or negative spherical values into the Patient Actual Refraction, the EYE REFRACTION software displays in the center of the screen a focal point located in the line of sight of the schematic eye, which is positioned either beyond or short of the virtual plane of the retina in cases of hypermetropia or myopia, respectively..

In the case of a spherical ametropia, the Front Power will present the meridians corresponding to the spherical value previously added. At the same time, the diopters that need to be corrected to achieve emmetropia, as well as the SER indicating the spherical equivalent for that ametropia, are shown in the Patient Residual Refraction. In the Sagittal View, the focal point in relation to the virtual plane of the retina can be observed from a side view.

As the spherical values are inserted into the Lens \# 1 and/or Lens \# 2 tabs of the CORRECTION function, spherical lenses appear in front of the eyeball and the focal point shifts forward in the line of sight of the schematic eye in the case of positive lenses or backwards in the case of negative lenses. Likewise, the displacement of the induced focal point can be observed in the Sagittal View.

On the other hand, when adding positive or negative values in the Patient Actual Refraction for the Cyl with its corresponding axis, the EYE REFRACTION software automatically displays in the central screen two focal lines located in the line of sight of the schematic eye, where it is able to assume several positions in respect to the virtual plane of the retina. These different possibilities may give rise to simple or compound myopic or hypermetropic astigmatism and even mixed astigmatism (equidistant or not). In these cases, the Front Power will present in its perpendicular meridians the values calculated by the algorithm. Similarly, the diopters that need to be corrected to achieve emmetropia will appear in the Patient Residual Refraction, whereas the SER and Sagittal View will continue to perform the same function as in the spherical ametropias (Figure 2). 


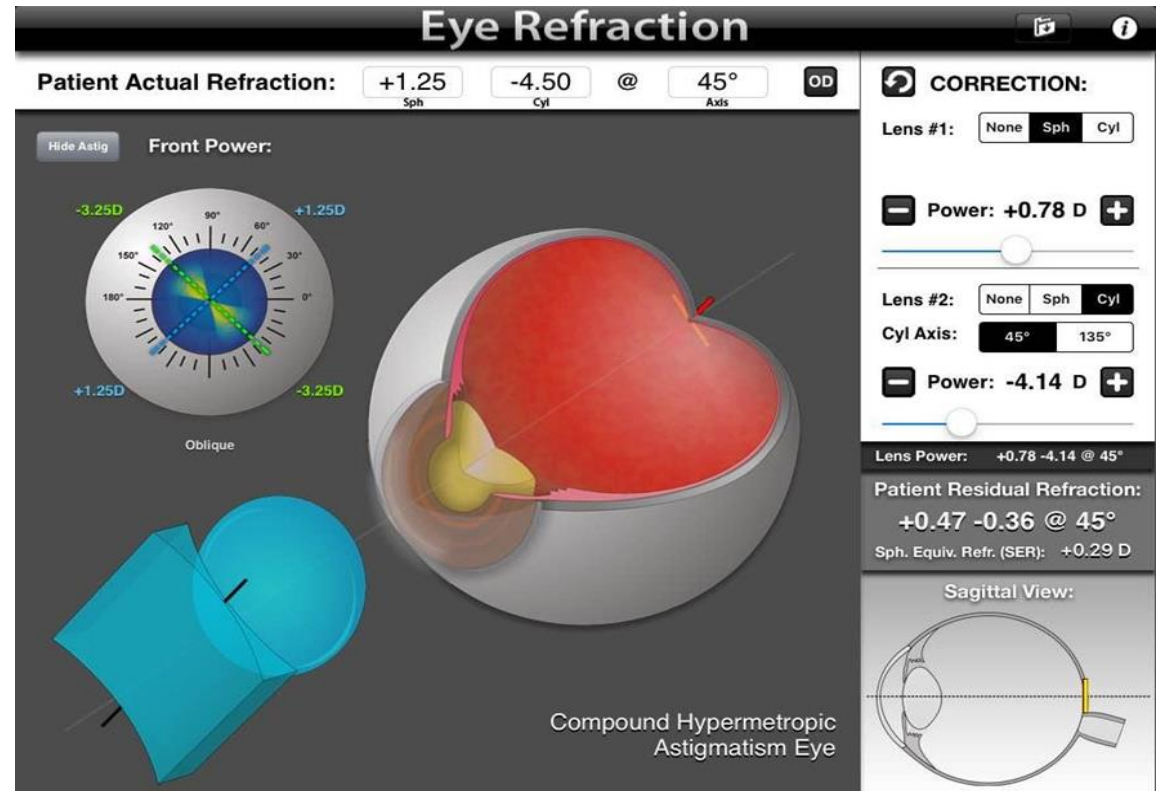

Figure 2: Simulation of the correction of a mixed astigmatism (Sph +1.25 / Cyl $\left.-4.50 / \mathrm{Axis} 45^{\circ}\right)$.

As spherical and/or cylindrical (positive or negative) values are added to Lens \#1 and/or Lens \#2 tabs of the CORRECTION function, both spherical and/or cylindrical lenses appear simultaneously in front of the schematic eye and the focal lines shift in the line of sight. If the lens inserted for partial correction of astigmatism is spherical, the focal lines will move forward or backward, maintaining the inter-focal distance between them.

However, if the lens is cylindrical, the focal line that will shift is the one parallel to its axis, keeping static the focal line that is perpendicular to the inserted axis. If the cylindrical lens is negative, the focal line will move backwards in the line of sight and forward if the cylindrical lens is positive. Likewise, the induced displacement of focal lines by the added lens can be simultaneously observed in the Sagital View (Figure 3).

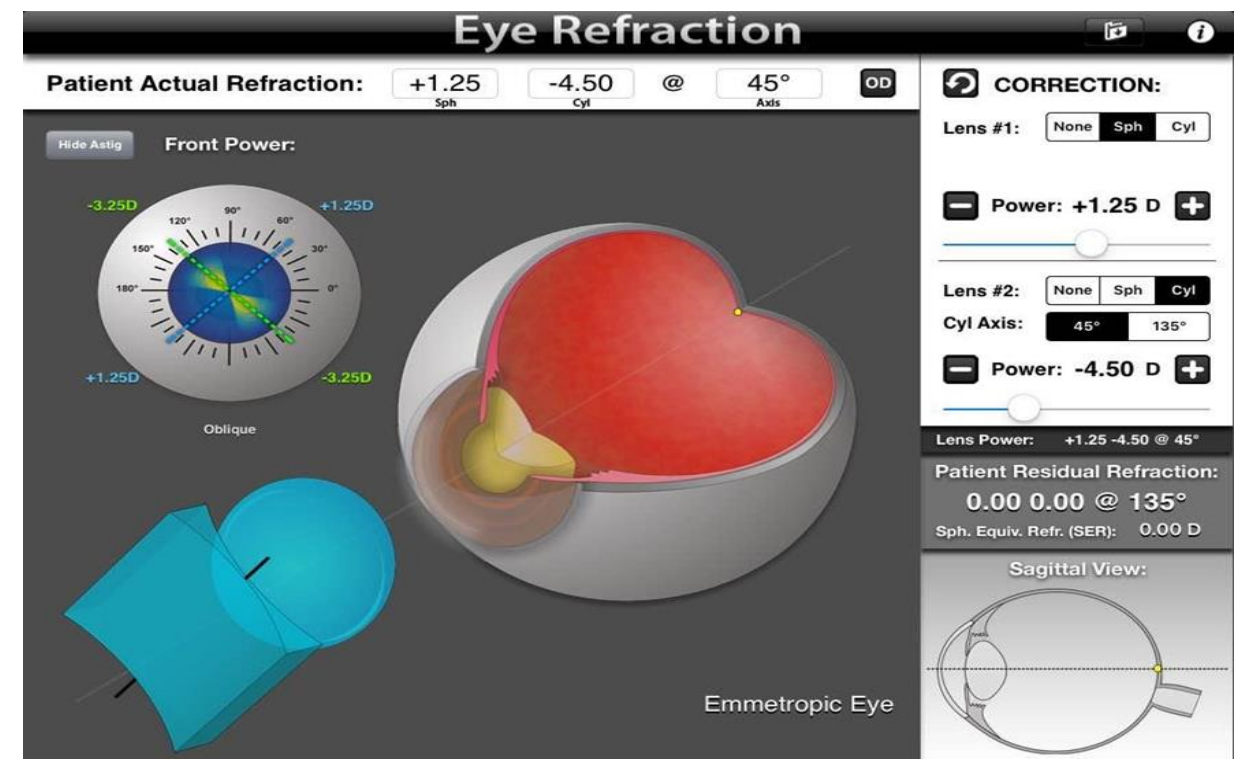

Figure 3: Corrected mixed astigmatism ( $\left.\mathrm{Sph}+1.25 / \mathrm{Cyl}-4.50 / \mathrm{Axis} 45^{\circ}\right)$. 


\subsection{Simulated failure test}

The EYE REFRACTION App was blindly and randomly tested by four experienced ophthalmologists, who were named I, II, III and IV. For ninety days the four ophthalmologists followed specific guidelines (TABLE 1) to detect possible failures through several simulations. Once the failures were identified, the software was corrected and retested by the same ophthalmologist who detected the respective failure. Thus, they were directed to simulate the same data. Once all the corrections were performed, the App was made available at the Apple Store for download through the following link: https://itunes.apple.com/br/app/eyerefraction/id467923909? $m$ t=8 (Figure 4).

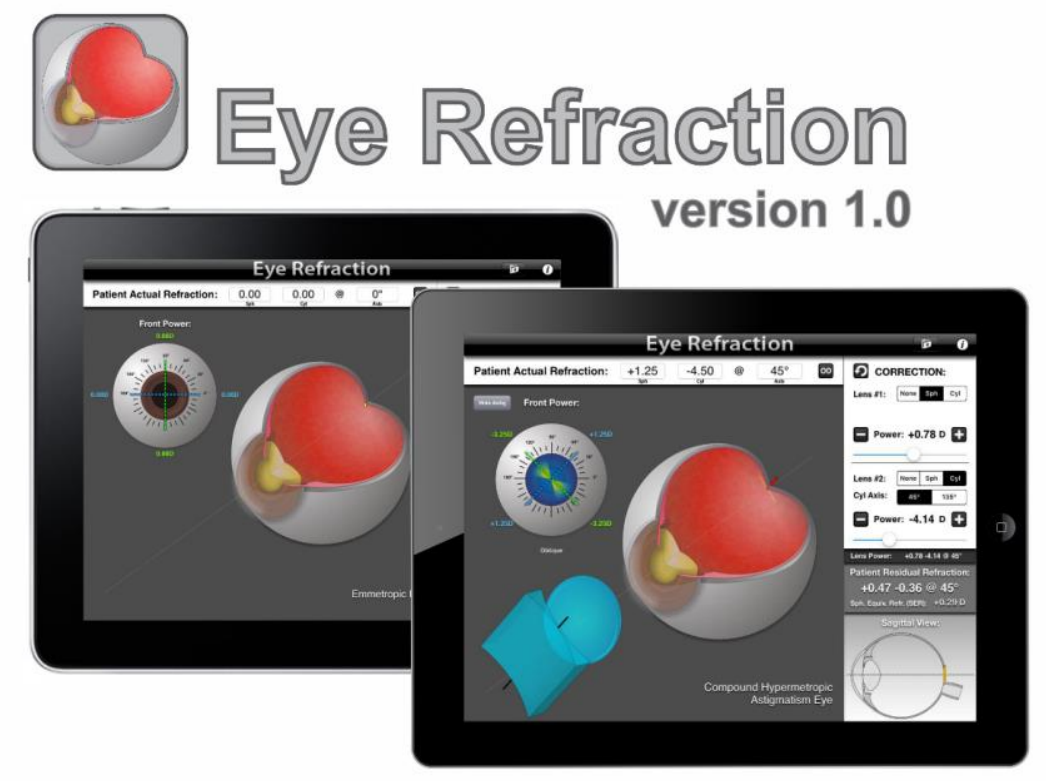

Figure 4: Eye Refraction - Simulator App for teaching refractometry (Ciência Ilustrada studio $®$, Natal, Brasil)

Table 1: Procedure guidelines for seeking failures

\section{Guidelines for the Simulations Using The Eye Refraction App}

1) Download The Eye Refraction App At The Apple Store Using The Provided Promocode

2) Read The Instructions Of How To Use The App On The "How To Use" Tab

3) Review All The Available Content Using The "Info" Tab

4) Simulate The Various Refractory Errors (Ametropia) By Randomly Inserting Values In The "Patient Actual Refraction", Using The Limit Of 10 Spherical Diopters And 10 Cylindrical Diopters As Shown Below:

- Perform 05 simulations of myopia;

- Perform 05 simulations of hypermetropia;

- Perform 05 simulations of simple myopic astigmatisms using positive cylinders;

- Perform 05 simulations of simple myopic astigmatisms using negative cylinders;

- Perform 05 simulations of compound myopic astigmatisms using positive cylinders;

- Perform 05 simulations of compound myopic astigmatisms using negative cylinders;

- Perform 05 simulations of simple hypermetropic astigmatisms using positive cylinders; 
- Perform 05 simulations of simple hypermetropic astigmatisms using negative cylinders;

- Perform 05 simulations of compound hypermetropic astigmatisms using positive cylinders;

- Perform 05 simulations of compound hypermetropic astigmatisms using negative cylinders;

- Perform 05 simulations of non-equidistant mixed astigmatism using positive cylinders;

- Perform 05 simulations of non-equidistant mixed astigmatism using negative cylinders;

- Perform 05 simulations of equidistant mixed astigmatism using positive cylinders;

- Perform 05 simulations of equidistant mixed astigmatism using negative cylinders.

5) After Adding The Values For Each Simulation, Please Check:

- Correct positions of points (in spherical ametropia) and focal lines (in astigmatism) on the central stage and Sagittal View;

- Consistency of the corrective lens positioning and indication of type of ametropia in the central stage;

- Consistency of the values in the Front Power and adequacy of Show Astigmatism;

- Consistency of the values in the CORRECTION column

6) Type It Out On The Supplied Cartesian Plane The Ametropia And Their Types That Presented Failures

\section{Results and Discussions}

After the development of the EYE REFRACTION App, it was tested by four ophthalmologists, where six failures were screened and detected by ophthalmologists I, III and IV. Two were observed by the ophthalmologist I when a simple and mixed myopic astigmatism were inserted, two by the ophthalmologist III during the analysis of a compound hypermetropic astigmatism and a simple myopic astigmatism, and two by the ophthalmologist IV during the representation of a mixed astigmatism and a simple hypermetropic astigmatism.

The ophthalmologist I observed that when inserting the refractometry data $\left(0.0-3.50 \times 90^{\circ}\right)$, which corresponds to a simple myopic astigmatism, the cylindrical lens interposed in front of the eye on the central stage was a positive cylinder rather than a negative one. The same ophthalmologist also found that when analyzing the Sagittal View of a mixed non-equidistant astigmatism with values of $\left(-0.75+5.25 \times 65^{\circ}\right)$, the focal lines were not at the corresponding points in the line of sight.

When inserting the values $\left(+1.75+2.00 \times 125^{\circ}\right)$ corresponding to a compound hypermetropic astigmatism, the ophthalmologist III pointed out an error in the positioning of the focal lines in the Sagittal View and another error in the representation of the Show Astigmatism function, when it simulated the simple myopic astigmatism $\left(-6.25+6.25 \times 15^{\circ}\right)$.

The ophthalmologist IV also reported two failures. The first occurred when the data referring to an equidistant mixed astigmatism $\left(+1.75-3.50 \times 75^{\circ}\right)$ was added, which did not have the correct representation in the Sagittal View. The second failure was detected during the analysis of simple hypermetropic astigmatism $\left(+3.75-3.75 \times 155^{\circ}\right)$, where the lenses interposed in front of the eye did not present the correct positioning (Figure 5). 


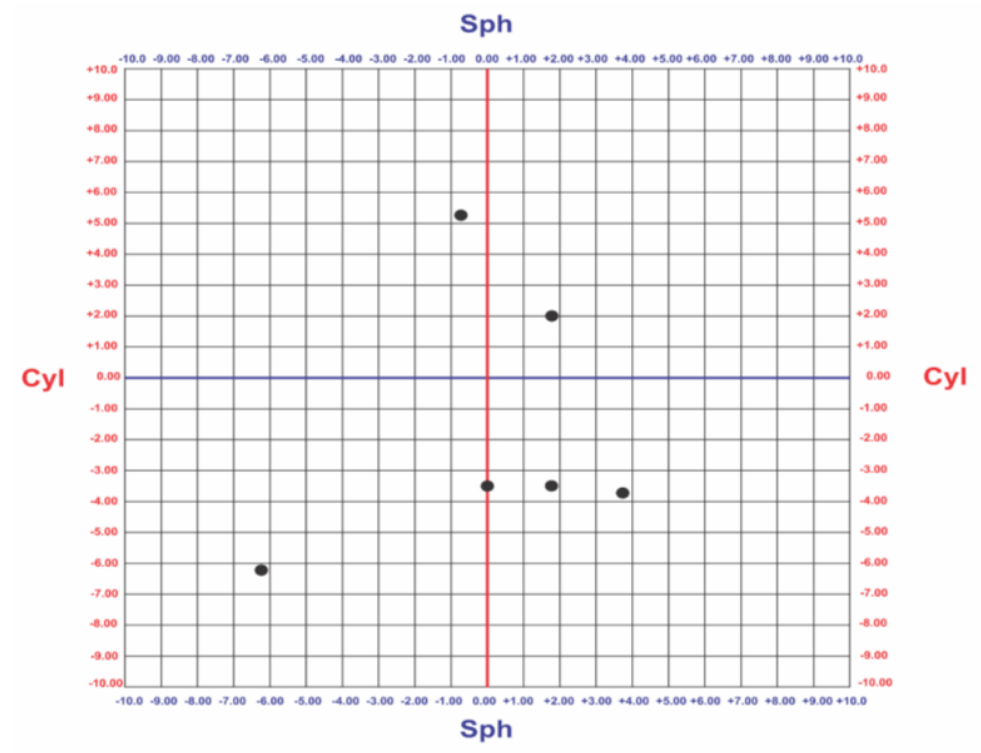

Figure 5: Graphical representation of the failures $(\bullet)$ detected during the testing phase (Sph spherical diopters, $\mathrm{Cyl}$ - cylindrical diopters)

Several educational technological innovations are developed with the purpose of contributing to the training of future ophthalmologists. ${ }^{9-18}$ among these innovations; we can highlight the use of softwares as multimedia tools or Apps, where they work as simulators for the training of direct and indirect ophthalmoscopy, as well as for developing skills for surgical procedures. Moreover, they can be used as associative technologies that guarantee better learning and lower risks to patients. However, very little is available for teaching refractometry.

Akaishi et al. validated a simulator for teaching optic fundus examination. ${ }^{19}$ The EYE Exam Simulator (Kyoto Kagaku Co. Ltd., Kyoto, Japan) consists of a manikin where slides are inserted with photos of normal and diseased retinas to be examined using the conventional direct ophthalmoscope.

Just recently, the Eyesi Direct Ophthalmoscope (VRmagic, GmbH, Mannheim, Germany®) was launched, which is another simulator that unlike the EYE Exam Simulator, it uses virtual reality for teaching direct ophthalmoscopy. ${ }^{20}$ Similarly, Schuppe et al. presented the Eyesi indirect ophthalmoscope simulator (VRmagic, GmbH, Mannheim, Germany) used to improve the diagnosis of retinal diseases through augmented reality during the training of ophthalmology residents. $^{21}$

In 2014, Leitritz and colleagues demonstrated superior performance during the learning of indirect ophthalmoscopy when ophthalmology residents used the Eyesi indirect ophthalmoscope simulator in comparison with the conventional indirect ophthalmoscope. ${ }^{22}$ Other reports demonstrate advantages of using technological innovations for teaching ophthalmology either during clinical teaching or during the training of surgical procedures such as facectomy. ${ }^{23-28}$

It is notorious the difficulty of understanding refractometry regarding the spatial visualization of the various refractive errors and their corrections. ${ }^{6}$ This requires an additional effort from the professors for teaching refratometry for undergraduate medical students as well as for residents 
in ophthalmology. However, scientific studies that address the development of softwares or simulators that aim to facilitate the understanding of refractive vices are rare.

The Aniseikonia Inspector software has been used by experienced ophthalmologists to presume the difference between the sizes of the images formed in the retinas of both eyes induced by the difference of the refractometry between them, known as aniseikonia. ${ }^{29,30}$ However, such software is not primarily aimed at teaching refractometry, but rather to help measuring aniseikonia in ophthalmological practice.

The idea of developing an App as a tool for teaching refractometry took place after observing that refractive errors are indirectly taught in most medical schools, which means that the reasoning starts with the correction in order to find refractive errors.

In the authors' conception, this seems to be the main source of difficulty for understanding refractometry. Thus, during the graphic development of the EYE REFRACTION App, the authors used a new approach, where in a single screen the user can observe in real time the refractive errors, their points or focal lines outside the retinal plane and their corrections. Such parameters can be determined in an interactive way.

The concern with the graphic design of the main screen and the interactive environment resulted in the difficulties perceived by one of the authors of this study, who is ophthalmologist and illustrator. This fact was of great importance because all the obstacles observed during the teaching-learning process were overcome through the perception of a professional who has already experienced the deficiencies present in the conventionally available teaching tools.

Based on these arguments, it is worth noting that the creation of an App for tablets represents a pioneering tool to effectively facilitate the learning process of refractometry.

Although the six failures detected during the testing phase were all promptly corrected, this procedure will not prevent future failures. In order to prevent possible failures during its use, the App developer has made available a link that the user can report the failures observed along the way so that they can be promptly corrected.

After 6 years of EYE REFRACTION's first release and 156 downloads in Latin America and The Caribbean, 102 in Europe, 71 in the USA and Canada, 39 in Asia Pacific and 13 in Africa, Middle East and India through www.itunesconnect.apple.com (restricted access), not a single failure was reported by its users. The App is currently in its fourth version and continuously seeking for improvements.

Unlike most simulators available for teaching ophthalmology, the EYE REFRACTION is at low cost and easy to use, as it provides the user with straightforward access to a simplified manual. In addition, because the software is embedded in a Tablet computer, its high mobility facilitates the teaching of refractometry in classrooms, clinics or even outside the teaching environment without the need for internet access. As a drawback, we can point out the availability of EYE REFRACTION only for IOS platform but with the possibility of being developed for Android. 


\section{Conclusions and Recommendations}

The future prediction is that EYE REFRACTION will represent the first of a series of Apps developed by "Ciencia Ilustrada studio" aimed to improve the teaching of refractometry, contributing directly to the training of future professionals and to the improvement of the ophthalmic health of the population.

Finally, a study is currently being conducted by our research group where the use of the EYE REFRACTION App is being compared with other teaching methods with the purpose of validating its usefulness.

\section{Acknowledgements}

This work was supported by "Science Illustrated Studio", which is a company incubated at "INOVA Metrópole" of the Digital Metropolis Institute of the Universidade Federal do Rio Grande do Norte, Brazil (IMD-UFRN).

\section{References}

[1] Succar T, Grigg J, Beaver HA, Lee AG. A systematic review of best practices in teaching ophthalmology to medical students. Surv Ophthalmol. 2016;61:83-94.

[2] World Health Organization, ed. Global initiative for the elimination of avoidable blindness: Action plan 2006-2011. Geneva: World Health Organization; 2007.

[3] Ting DS, Sim SS, Yau CW, Rosman M, Aw AT, Yeo IY. Ophthalmology simulation for undergraduate and postgraduate clinical education. Int J Ophthalmol. 2016;9:920-924.

[4] Cook DA, Hatala R, Brydges R, et al. Technology-enhanced simulation for health professions education: A systematic review and meta-analysis. JAMA. 2011;306:978-988.

[5] Solverson DJ, Mazzoli RA, Raymond WR, et al. Virtual reality simulation in acquiring and differentiating basic ophthalmic microsurgical skills. Simul Healthc. 2009;4:98-103.

[6] Donaldson PJ, Grey AC, Maceo Heilman B, Lim JC, Vaghefi E. The physiological optics of the lens. Prog Retin Eye Res. 2017;56:e1-e24.

[7] Clarkson JG. Training in ophthalmology is critical for all physicians. Arch Ophthalmol. 2003; 121:1327.

[8] Stern GA. Teaching ophthalmology to primary care physicians. The association of university professors of ophthalmology education committee. Arch Ophthalmol. 1995; 113:722-724.

[9] Xie P, Hu Z, Zhang X, et al. Application of 3-dimensional printing technology to construct an eye model for fundus viewing study. PLoS One. 2014; 9:e109373.

[10] Thomsen AS, Subhi Y, Kiilgaard JF, la Cour M, Konge L. Update on simulation-based surgical training and assessment in ophthalmology: A systematic review. Ophthalmology. 2015; 122:1111-1130.e1.

[11] Moisseiev E, Michaeli A. Simulation of neodymium:YAG posterior capsulotomy for ophthalmologists in training. J Cataract Refract Surg. 2014; 40:175-178.

[12] Selvander M, Asman P. Stereoacuity and intraocular surgical skill: Effect of stereoacuity level on virtual reality intraocular surgical performance. J Cataract Refract Surg. 2011; 37:2188-2193.

[13] Saleh GM, Theodoraki K, Gillan S, et al. The development of a virtual reality training programme for ophthalmology: Repeatability and reproducibility (part of the international forum for ophthalmic simulation studies). Eye (Lond). 2013; 27:1269-1274.

[14] Sikder S, Tuwairqi K, Al-Kahtani E, Myers WG, Banerjee P. Surgical simulators in cataract surgery training. Br J Ophthalmol. 2014; 98:154-158. 
[15] Baxter JM, Lee R, Sharp JA, Foss AJ, Intensive Cataract Training Study Group. Intensive cataract training: A novel approach. Eye (Lond). 2013; 27:742-746.

[16] Yong JJ, Migliori ME, Greenberg PB. A novel preclinical course in ophthalmology and ophthalmic virtual surgery. Med Health R I. 2012; 95:345-348.

[17] Le TD, Adatia FA, Lam WC. Virtual reality ophthalmic surgical simulation as a feasible training and assessment tool: Results of a multicentre study. Can J Ophthalmol. 2011; 46:56-60.

[18] Selvander M, Asman P. Virtual reality cataract surgery training: Learning curves and concurrent validity. Acta Ophthalmol. 2012; 90:412-417.

[19] Akaishi Y, Otaki J, Takahashi O, et al. Validity of direct ophthalmoscopy skill evaluation with ocular fundus examination simulators. Can J Ophthalmol. 2014; 49:377-381.

[20] Hoeg TB, Sheth BP, Bragg DS, Kivlin JD. Evaluation of a tool to teach medical students directs ophthalmoscopy. WMJ. 2009; 108:24-26.

[21] Schuppe O, Wagner C, Koch F, Manner R. EYESi ophthalmoscope - a simulator for indirect ophthalmoscopic examinations. Stud Health Technol Inform. 2009; 142:295-300.

[22] Leitritz MA, Ziemssen F, Suesskind D, et al. Critical evaluation of the usability of augmented reality ophthalmoscopy for the training of inexperienced examiners. Retina. 2014; 34:785-791.

[23] Pokroy R, Du E, Alzaga A, et al. Impact of simulator training on resident cataract surgery. Graefes Arch Clin Exp Ophthalmol. 2013; 251:777-781.

[24] Belyea DA, Brown SE, Rajjoub LZ. Influence of surgery simulator training on ophthalmology resident phacoemulsification performance. J Cataract Refract Surg. 2011; 37:1756-1761.

[25] Ament CS, Henderson BA. Optimizing resident education in cataract surgery. Curr Opin Ophthalmol. 2011; 22:64-67.

[26] Daly MK, Gonzalez E, Siracuse-Lee D, Legutko PA. Efficacy of surgical simulator training versus traditional wet-lab training on operating room performance of ophthalmology residents during the capsulorhexis in cataract surgery. J Cataract Refract Surg. 2013; 39:1734-1741.

[27] Selvander M, Asman P. Ready for OR or not? Human reader supplements Eyesi scoring in cataract surgical skills assessment. Clin Ophthalmol. 2013; 7:1973-1977.

[28] McCannel CA, Reed DC, Goldman DR. Ophthalmic surgery simulator training improves resident performance of capsulorhexis in the operating room. Ophthalmology. 2013; 120:2456-2461.

[29] Antona B, Barra F, Barrio A, Gonzalez E, Sanchez I. The validity and repeatability of the new aniseikonia test. Optom Vis Sci. 2006; 83:903-909.

[30] Antona B, Barra F, Barrio A, Gonzalez E, Sanchez I. Validity and repeatability of a new test for aniseikonia. Invest Ophthalmol Vis Sci. 2007; 48:58-62.

*Corresponding author.

Prof. Dr. Irami Araújo Filho

Full Professor of the Department of Surgery and Titular Chief of the Laboratory of Simulation in the

Teaching of Health of the Potiguar University, Brazil - Laureate International Universities (UnP); Full

Professor of the Department of Surgery, PhD in Health Sciences, Full Professor of the Post Graduate

Program in Biotechnology at Potiguar University - Laureate International Universities, Natal, Rio

Grande do Norte, Brazil

Natal - RN, 59020-650, Brazil

Phone number: +55 84988760206

orcid.org/0000-0003-2471-7447

$\mathrm{R}^{6}$ https://wwww.researchgate.net/profile/Irami_Filho

Email: irami.filho@uol.com.br 